\section{(2) OPEN ACCESS}

\title{
Short-term effects of outdoor air pollution on acute ischaemic stroke occurrence: a case-crossover study in Tianjin, China
}

\author{
Xuemei Qi (D) ,' Zhongyan Wang, ${ }^{2}$ Xiaokun Guo, ${ }^{2}$ Xiaoshuang Xia, ${ }^{1}$ Juanjuan Xue, \\ Guojing Jiang, ${ }^{2}$ Yumeng Gu, ${ }^{1}$ Suqin Han, ${ }^{3}$ Qing Yao, ${ }^{3}$ Ziying Cai, ${ }^{3}$ Xiaojia Wang, ${ }^{3}$ \\ Lin Wang, ${ }^{2}$ Sean $X$ Leng, $^{4}$ Xin Li (D) ${ }^{1}$
}

- Additional material is published online only. To view, please visit the journal online (http://dx.doi.org/10.1136/ oemed-2019-106301).

${ }^{1}$ Department of Neurology, The Second Hospital of Tianjin Medical University, Tianjin, China

${ }^{2}$ Department of Geriatrics, The Second Hospital of Tianjin Medical University, Tianjin, China

${ }^{3}$ CMA-NKU Cooperative Laboratory for Atmospheric Environment-Health Research (CLAER/CMA-NKU), Tianjin Environmental Meteorology Center, Tianjin, China ${ }^{4}$ Division of Geriatric Medicine and Gerontology, Johns Hopkins University School of Medicine, Baltimore, Maryland, USA

\section{Correspondence to} Dr Xin Li, Department of Neurology, The Second Hospital of Tianjin Medical University, Tianjin 300211, China; lixinsci@126.com and Dr Sean X Leng, Division of Geriatric Medicine and Gerontology, Johns Hopkins University School of Medicine, Baltimore, Maryland, USA; sleng1@jhmi.edu

Received 4 November 2019 Revised 7 July 2020 Accepted 2 August 2020 Published Online First 27 August 2020

\section{ABSTRACT}

Objective Ambient air pollution is associated with ischaemic stroke incidence. However, most of the previous studies used stroke-related hospital admission rather than stroke onset itself. This study aimed to evaluate the relationship between ambient air pollutant exposures and acute ischaemic stroke based on the timing of symptom onset.

Methods A time-stratified, case-crossover analysis was performed among 520 patients who had ischaemic stroke admitted to the Second Hospital of Tianjin Medical University (Tianjin, China) between 1 April 2018 and 31 March 2019 (365 days). Daily air pollutant concentrations of particulate matter with aerodynamic diameter $2.5 \mu \mathrm{m}$, particulate matter with aerodynamic diameter $10 \mu \mathrm{m}$ (PM10), sulfur dioxide, nitrogen dioxide, carbon monoxide and ozone were obtained from fixedsite monitoring stations. We used conditional logistic regression to estimate OR and $95 \% \mathrm{Cl}$ corresponding to an increase in IQR of each air pollutant after adjusting for the effects of temperature and relative humidity.

Results Overall, a higher risk of ischaemic stroke was found between April and September. During this period PM10 was associated with an increased risk of ischaemic stroke (1-day lag: $\mathrm{OR}=1.49,95 \% \mathrm{Cl} 1.09$ to 2.02; 3-day mean: $O R=1.58,95 \% \mathrm{Cl} 1.09$ to 2.29 ) among patients between 34 and 70 years old. Positive associations were also observed between PM10 (1-day lag: OR=1.51, $95 \% \mathrm{Cl} 1.10$ to 2.07 ; 3-day mean: $O R=1.57,95 \% \mathrm{Cl}$ 1.08 to 2.29 ), ozone (1-day lag: $O R=1.83,95 \% \mathrm{Cl} 1.16$ to 2.87 ; 3-day mean: $\mathrm{OR}=1.90,95 \% \mathrm{Cl} 1.06$ to 3.42 ) and ischaemic stroke occurrence among those with hyperlipidaemia.

Conclusion Our results suggest that air pollution is associated with a higher risk of ischaemic stroke in younger people or people with hyperlipidemia. These findings still need to be further investigated.

\section{INTRODUCTION}

(C) Author(s) (or their employer(s)) 2020. Re-use permitted under CC BY-NC. No commercial re-use. See rights and permissions. Published by BMJ.

To cite: Qi X, Wang Z, Guo X et al. Occup Environ Med 2020;77:862-867.
Stroke is a major cause of death and disability worldwide, and stroke burden is particularly high in low-income and middle-income countries. ${ }^{1}$ In China, stroke has been the leading cause of death and disability in recent years. ${ }^{2}$ A nationwide population-based study showed that the highest incidence of stroke was found in the northeast region of China, including Tianjin, and ischaemic

\section{Key messages}

What is already known about this subject?

- Increasing evidence suggests an association between ambient air pollution and ischaemic stroke.

- Most of the previous studies used stroke-related hospital admission rather than stroke onset itself.

\section{What are the new findings?}

- Higher air pollution-associated risk of ischaemic stroke onset was found between April and September.

- During this period, particulate matter with aerodynamic diameter $10 \mu \mathrm{m}$ (PM10) was associated with an increased risk of ischaemic stroke among patients between 34 and 70 years old.

- PM10 and ozone were associated with an increased risk of ischaemic stroke among those with hyperlipidaemia.

How might this impact on policy or clinical practice in the foreseeable future?

- Certain specific patient subgroups may be at increased risk of air pollution-related ischaemic stroke.

- Improving air quality may help prevent or reduce stroke occurrence, and some simple measures can be taken to reduce individual stroke risk, such as avoiding walking or exercising along traffic roads.

stroke constituted approximately $70 \%$ of all incident and prevalent strokes. ${ }^{3}$ Common risk factors of ischaemic stroke include hypertension, high cholesterol level, smoking and alcohol consumption. ${ }^{3}$ Early detection and effective treatment of these modifiable risk factors constitute major current public health measures for the prevention and control of ischaemic stroke.

Many epidemiological and experimental studies have found adverse effects of air pollution on health. ${ }^{5}$ While most early studies focused on respiratory diseases such as asthma, more recent studies showed that short-term or long-term air pollutant exposures contributed to the onset and aggravation 
of cerebrovascular diseases, especially of ischaemic stroke. ${ }^{5-8}$ For example, hospital admissions for ischaemic stroke were associated with increased concentrations of ambient air pollutants. Positive associations have been observed for both gaseous air pollutants including sulfur dioxide $\left(\mathrm{SO}_{2}\right)$, nitrogen dioxide $\left(\mathrm{NO}_{2}\right)$, carbon monoxide $(\mathrm{CO})$, ozone $\left(\mathrm{O}_{3}\right)$ and particulate air pollutants, including particulate matter with aerodynamic diameter $10 \mu \mathrm{m}$ (PM10) and particulate matter with aerodynamic diameter $2.5 \mu \mathrm{m}$ (PM2.5), in many epidemiological evidence. ${ }^{9-13}$ Based on these and other studies, it is generally believed that hospitalisation data on stroke could better evaluate the temporal sequence between air pollutant exposures and clinical presentation of stroke and increase statistical power. ${ }^{8} 11$ However, some studies have yielded inconsistent results on the association between air pollution and ischaemic stroke occurrence, possibly due to differences in population susceptibility, air pollution levels or components, and meteorological characteristics. ${ }^{10}$ 14-16 It should also be pointed out that these risk estimates of air pollutants were based on hospitalisation time rather than the time of ischaemic stroke onset, and studies showed that time to hospital after symptom onset of patients were different in different regions partially due to differences in the knowledge of seeking immediate medical help. ${ }^{17}$ These may lead to misclassification of time and influence the evaluation of adverse effects of air pollutants. ${ }^{8} 18$

In the present study, we recorded the onset time of ischaemic stroke symptoms of each patient to examine the association between short-term air pollutant exposures and onset of ischaemic stroke in a stroke unit in Tianjin, China, using a timestratified, case-crossover design.

\section{MATERIALS AND METHODS Clinical data}

Data on 525 consecutive patients with a final diagnosis of acute ischaemic stroke confirmed by MRI and/or CT were collected. All patients were admitted to the stroke unit of the Second Hospital of Tianjin Medical University (Tianjin, China) between 1 April 2018 and 31 March 2019. Data were reviewed and recorded by two neurologists and analysed in retrospect. Five of the 525 patients were excluded from the study due to incomplete data, and 520 patients were included in the final analysis. The time of symptom onset was reported by the patients and/or caregivers. For some patients considering thrombolysis, perfusion-weighted imaging was also performed to compare with diffusion-weighted imaging in order to determine ischaemic penumbra and reperfusion time windows. The average distance between where the study participants resided and the hospital was $8 \mathrm{~km}$. The median time to hospital after symptom onset was 15.5 hours (ranging from $30 \mathrm{~min}$ to 14 days), with 57 (11.0\%) patients admitted within 3 hours after the onset of stroke, 240 (46.2\%) within 12 hours and 267 (51.3\%) within 24 hours. Nearly half $(253,48.7 \%)$ the patients were admitted over 1 day after stroke onset. It would be beneficial to use the time of stroke onset but not time of hospital admission in the study.

Demographic and clinical data included age, sex, medical history (hypertension, diabetes mellitus, hyperlipidaemia, atrial fibrillation, smoking status, alcohol consumption and medication use) and certain laboratory findings, which were obtained by reviewing the medical records of the current stroke admission if the patients were admitted to our hospital for the first time. If the patients were readmitted, past medical records were also reviewed dating back to 2004 . No protected health information was collected as data.

\section{Air pollution and meteorological parameters}

Air pollution data and meteorological data, including daily mean levels of temperature and relative humidity, between 30 March 2018 and 31 March 2019 (367 days) were provided by the Tianjin Environmental Meteorology Center of Tianjin Meteorological Bureau. Air pollution measurements were the average from the six fixed-site continuous monitoring stations located in the north of the hospital, within $15 \mathrm{~km}$. The air pollutants used in this study included the daily mean levels of PM10, PM2.5, $\mathrm{NO}_{2}, \mathrm{CO}$ and $\mathrm{O}_{3}$. The mean values of air pollutants were calculated over 24-hour periods, except for $\mathrm{O}_{3}$ which was computed only on 8-hour daytime periods. Daily weather data on temperature and relative humidity were used as adjustment factors in the following multivariable conditional logistic regression models to allow for potential confounding effects of meteorological parameters. $^{811}$

\section{Study design}

We used a time-stratified, case-crossover design to study the associations between outdoor air pollution and acute ischaemic stroke occurrence, which is one of the most commonly used methods for studying the health-related effects of air pollution. ${ }^{19}$ The study design was an adaptation of a case-control study, in which each case served as its own control. For each case of ischaemic stroke, outdoor air pollution exposure on the case day (the day of stroke onset) was compared with their exposure on referent days. The study referent periods were chosen using a time-stratified design. Three or four referent days were selected from the same day of the week in the same month and the same year as the case day $(7,14,21$ and 28 days before or after the case day). This study design allowed for controlling the effects of time trends, seasonality and day of the week and for matching the time-invariant characteristics of the patients. ${ }^{8} 20$

\section{Statistical methods}

Spearman's correlation tests were used to estimate the associations between air pollutants and meteorological variables. We used conditional logistic regression to estimate the risk effect of each air pollutant after adjusting for meteorological parameters (air temperature and humidity), which was presented by OR and the corresponding 95\% CI. The ORs were expressed according to an increase in the IQR of daily mean pollutant levels during the study period. Further stratified analyses were performed to explore whether the associations between air pollutants and ischaemic stroke occurrence were different by season (AprilSeptember, October-March), age (34-70 years old, $\geq 70$ years old) and stroke risk factor (hyperlipidaemia) to identify individuals susceptible to the effects of air pollutant exposures. Different time lags for air pollutants were also considered in our analysis, including same-day, 1-day lag and 3-day average. The 3 -day average was calculated by the pollutant levels on the same day, 1 day before and 2 days before the ischaemic stroke onset (or the referent days), which could be used to estimate the shortterm cumulative effects of air pollution. We also evaluated the differences among risk estimates in the stratified analysis using t-test. ${ }^{8}{ }^{21} \mathrm{P}$ values with a two-tailed significance level less than 0.05 were considered statistically significant. All statistical analyses were performed using SPSS V.20.0 statistics software. ${ }^{22}$

\section{RESULTS}

A total of 520 patients with acute ischaemia admitted from 1 April 2018 to 31 March 2019 were included in our study. The demographic characteristics of the subjects are shown in table 1. 
Table 1 Demographic characteristics of study subjects

\begin{tabular}{lc}
\hline Characteristics & Acute ischaemic stroke $(\mathrm{N}=520)$ \\
\hline Age (mean \pm SD) & $69.9 \pm 11.1$ \\
\hline $34-70(\%)$ & $269(51.7)$ \\
\hline$\geq 70(\%)$ & $251(48.3)$ \\
\hline Gender (\%) & $331(63.7)$ \\
\hline Male & $189(36.3)$ \\
\hline Female & \\
History of risk factors (\%) & $361(69.4)$ \\
\hline Hypertension & $151(29.0)$ \\
\hline Diabetes mellitus & $278(53.5)$ \\
\hline Hyperlipidaemia & $56(10.8)$ \\
\hline Atrial fibrillation & $181(34.8)$ \\
\hline Smoking & $134(25.8)$ \\
\hline Alcohol consumption & \\
\hline Season* (\%) & $281(54.0)$ \\
\hline Warm (April-September) & $239(46.0)$ \\
\hline Cold (October-March) &
\end{tabular}

${ }^{*}$ Time-related variables were based on the time of stroke symptom onset.

The mean age of the subjects was $69.9 \pm 11.1$ (SD) years old, of whom $51.7 \%$ (269) were $34-70$ years old. There were a total of $331(63.7 \%)$ male patients and 189 (36.3\%) female patients. As regards medical history, there were 361 (69.4\%) with hypertension, 151 (29.0\%) with diabetes mellitus, 278 (53.5\%) with hyperlipidaemia, 56 (10.8\%) with atrial fibrillation, 181 (34.8\%) with smoking history and 134 (25.8\%) with alcohol consumption history. Among all subjects, 281 (54.0\%) ischaemic strokes occurred from April to September and 239 (46.0\%) occurred from October to March in the following year during the study period.

Statistical data on air pollutants (PM2.5, PM10, $\mathrm{SO}_{2}, \mathrm{CO}$, $\mathrm{NO}_{2}, \mathrm{O}_{3}$ ) and meteorological parameters (temperature, relative humidity) during the study period are summarised in online supplemental appendix table 1 . The daily concentrations of air pollutants in Tianjin were much higher than that reported in developed countries. ${ }^{11}{ }^{14}$ Seasonal Pearson correlations between the daily levels of air pollution and meteorological variables are presented in online supplemental appendix table 2 . The daily concentrations of PM2.5, PM10, $\mathrm{SO}_{2}, \mathrm{CO}$ and $\mathrm{NO}_{2}$ were positively associated with each other, and the correlation between PM10 and CO did not reach statistical significance during the warm season. Temperature and humidity were positively associated with each other. $\mathrm{O}_{3}$, temperature and humidity were positively or negatively associated with other air pollutants (PM2.5, PM10, $\mathrm{SO}_{2}, \mathrm{CO}$ and $\mathrm{NO}_{2}$ ).

Age differences in the association between air pollution and ischaemic stroke occurrence are shown in table 2. The adjusted OR corresponding to an interquartile increase of 1-day lag PM10 was 1.49 (95\% CI 1.09 to 2.02) among patients between 34 and 70 years old from April to September, and a positive association of 3-day average exposure to PM10 was also observed (OR=1.58, 95\% CI 1.09 to 2.29). In contrast, there were no significant associations between air pollutant exposures

Table 2 Adjusted OR for stroke unit admissions for acute ischaemic stroke according to an increase in IQR of each air pollutant by age and season, in Tianjin, from 1 April 2018 to 31 March 2019

\begin{tabular}{|c|c|c|c|c|c|}
\hline & & $<70$ years old $(n=269)$ & $\geq 70$ years old $(n=251)$ & $<70$ years old (April-September) $(n=150)$ & $<70$ years old (October-March) $(n=119)$ \\
\hline Pollutants & IQR & OR $(95 \% \mathrm{Cl})$ & OR $(95 \% \mathrm{Cl})$ & OR $(95 \% \mathrm{Cl})$ & OR $(95 \% \mathrm{Cl})$ \\
\hline \multicolumn{6}{|l|}{ PM2.5 } \\
\hline Same-day & 37.0 & $1.00(0.99$ to 1.00$)$ & $0.99(0.99$ to 1.00$)$ & $1.30(0.94$ to 1.79$)$ & 1.00 (0.99 to 1.01$)$ \\
\hline 1-day lag & & $1.00(0.99$ to 1.01$)$ & $0.99(0.98$ to 1.00$)$ & $1.38(0.99$ to 1.98$)$ & $1.00(0.99$ to 1.00$)$ \\
\hline 3-day & & $1.00(0.99$ to 1.01$)$ & $1.00(0.99$ to 1.00$)$ & $1.00(0.95$ to 1.05$)$ & $1.00(0.99$ to 1.0$)$ \\
\hline \multicolumn{6}{|l|}{ PM10 } \\
\hline Same-day & 55.5 & 0.96 (0.80 to 1.15$)$ & 0.85 (0.71 to 1.02$)$ & 1.25 (0.92 to 1.70$)$ & 0.88 (0.66 to 1.19$)$ \\
\hline 1-day lag & & 1.00 (0.99 to 1.01$)$ & 0.99 (0.98 to 1.00$)$ & $1.49(1.09 \text { to } 2.02)^{*}$ & 1.00 (0.99 to 1.00$)$ \\
\hline 3-day & & $0.98(0.80$ to 1.20$)$ & 0.85 (0.70 to 1.03$)$ & $1.58(1.09 \text { to } 2.29)^{*}$ & 0.88 (0.65 to 1.20$)$ \\
\hline \multicolumn{6}{|l|}{$\mathrm{SO}_{2}$} \\
\hline Same-day & 9.0 & $0.99(0.96$ to 1.03$)$ & $0.97(0.93$ to 1.01$)$ & $1.13(0.82$ to 1.56$)$ & 0.99 (0.96 to 1.04$)$ \\
\hline 1-day lag & & 0.99 (0.96 to 1.03$)$ & 0.98 (0.95 to 1.01$)$ & 1.07 (0.78 to 1.47$)$ & 1.00 (0.95 to 1.05$)$ \\
\hline 3-day & & 1.00 (0.95 to 1.04$)$ & $0.96(0.92$ to 1.00$)$ & 1.15 (0.77 to 1.71$)$ & 1.01 (0.95 to 1.07$)$ \\
\hline \multicolumn{6}{|l|}{$\mathrm{CO}$} \\
\hline Same-day & 0.4 & $1.10(0.70$ to 1.73$)$ & 0.94 (0.60 to 1.48$)$ & $1.10(0.82$ to 1.48$)$ & $1.02(0.64$ to 1.63$)$ \\
\hline 1-day lag & & 1.01 (0.62 to 1.64$)$ & 0.95 (0.59 to 1.53$)$ & 1.07 (0.79 to 1.44$)$ & 1.36 (0.80 to 2.31$)$ \\
\hline 3-day & & 1.03 (0.56 to 1.88$)$ & 0.86 (0.53 to 1.39$)$ & 1.14 (0.83 to 1.57$)$ & 1.24 (0.61 to 2.50$)$ \\
\hline \multicolumn{6}{|l|}{$\mathrm{NO}_{2}$} \\
\hline Same-day & 29.0 & 1.00 (0.99 to 1.01$)$ & 0.99 (0.97 to 1.01$)$ & 1.17 (0.79 to 1.75$)$ & 1.00 (0.99 to 1.02$)$ \\
\hline 1-day lag & & 0.99 (0.98 to 1.01$)$ & 0.99 (0.98 to 1.00$)$ & 1.02 (0.72 to 1.44$)$ & 0.99 (0.98 to 1.01$)$ \\
\hline 3-day & & 1.00 (0.99 to 1.02$)$ & $0.99(0.97$ to 1.00$)$ & 1.10 (0.70 to 1.72$)$ & 1.00 (0.98 to 1.02$)$ \\
\hline \multicolumn{6}{|l|}{$\mathrm{O}_{3}$} \\
\hline Same-day & 99.5 & $0.83(0.61$ to 1.11$)$ & $0.87(0.64$ to 1.18$)$ & $1.15(0.78$ to 1.71$)$ & 0.75 (0.47 to 1.19$)$ \\
\hline 1-day lag & & 0.97 (0.74 to 1.27$)$ & 0.92 (0.66 to 1.27$)$ & 1.49 (0.98 to 1.90$)$ & 0.72 (0.45 to 1.16$)$ \\
\hline 3-day & & 1.04 (0.69 to 1.55$)$ & 0.84 (0.57 to 1.24$)$ & $1.11(0.72$ to 1.72$)$ & $0.88(0.45$ to 1.74$)$ \\
\hline
\end{tabular}

All ORs were adjusted for same-day, 1-day lag and 3-day temperature and relative humidity, respectively.

${ }^{*} \mathrm{P}<0.05$.

$\mathrm{CO}$, carbon monoxide; $\mathrm{NO}_{2}$, nitrogen dioxide; $\mathrm{O}_{3^{\prime}}$ ozone; $\mathrm{PM}$, particulate matter; $\mathrm{SO}_{2}$, sulfur dioxide. 
Table 3 Adjusted OR for stroke unit admissions for acute ischaemic stroke according to an increase in IQR of each air pollutant by hyperlipidaemia and season, in Tianjin from 1 April 2018 to 31 March 2019

\begin{tabular}{|c|c|c|c|c|c|}
\hline & & Hyperlipidaemia $(n=289)$ & No hyperlipidaemia $(n=231)$ & $\begin{array}{l}\text { Hyperlipidaemia (April- } \\
\text { September) }(n=157)\end{array}$ & $\begin{array}{l}\text { Hyperlipidaemia (October- } \\
\text { March) }(n=132)\end{array}$ \\
\hline Pollutants & IQR & OR $(95 \% \mathrm{Cl})$ & OR $(95 \% \mathrm{Cl})$ & OR $(95 \% \mathrm{Cl})$ & OR $(95 \% \mathrm{Cl})$ \\
\hline \multicolumn{6}{|l|}{ PM2.5 } \\
\hline Same-day & 37.0 & 1.00 (0.99 to 1.00$)$ & 1.00 (0.99 to 1.00$)$ & $1.04(0.77$ to 1.39$)$ & $0.99(0.99$ to 1.00$)$ \\
\hline 1-day lag & & $1.00(0.99$ to 1.00$)$ & $0.99(0.98$ to 1.00$)$ & 1.18 (0.85 to 1.65$)$ & $1.00(0.99$ to 1.00$)$ \\
\hline 3-day & & $1.00(0.99$ to 1.00$)$ & $0.99(0.98$ to 1.00$)$ & 1.02 (0.95 to 1.08$)$ & $1.00(0.99$ to 1.00$)$ \\
\hline \multicolumn{6}{|l|}{ PM10 } \\
\hline Same-day & 55.5 & 0.85 (0.71 to 1.00$)$ & 0.98 (0.81 to 1.19$)$ & 1.04 (0.79 to 1.36$)$ & $0.84(0.65$ to 1.10$)$ \\
\hline 1-day lag & & $1.00(0.99$ to 1.00$)$ & 0.99 (0.99 to 1.00$)$ & $1.51(1.10 \text { to } 2.07)^{*}$ & 0.99 (0.99 to 1.00$)$ \\
\hline 3-day & & 0.91 (0.76 to 1.08$)$ & 0.86 (0.70 to 1.06$)$ & $1.57(1.08 \text { to } 2.29)^{*}$ & 0.82 (0.63 to 1.06$)$ \\
\hline \multicolumn{6}{|l|}{$\mathrm{SO}_{2}$} \\
\hline Same-day & 9.0 & 0.99 (0.96 to 1.02$)$ & 0.99 (0.95 to 1.03$)$ & 1.21 (0.88 to 1.68$)$ & 0.99 (0.95 to 1.03$)$ \\
\hline 1-day lag & & 0.98 (0.95 to 1.01$)$ & 0.98 (0.95 to 1.03$)$ & 1.20 (0.87 to 1.65 ) & $0.98(0.95$ to 1.02$)$ \\
\hline 3-day & & 0.99 (0.94 to 1.03$)$ & 0.97 (0.92 to 1.02$)$ & 1.31 (0.89 to 1.94$)$ & 0.98 (0.93 to 1.04$)$ \\
\hline \multicolumn{6}{|l|}{$\mathrm{CO}$} \\
\hline Same-day & 0.4 & $1.13(0.75$ to 1.71$)$ & $0.88(0.51$ to 1.53$)$ & 1.09 (0.83 to 1.43$)$ & 0.89 (0.50 to 1.61$)$ \\
\hline 1-day lag & & $1.00(0.64$ to 1.56$)$ & $0.78(0.45$ to 1.37$)$ & 1.12 (0.85 to 1.48$)$ & $0.79(0.45$ to 1.40$)$ \\
\hline 3-day & & 0.95 (0.59 to 1.54$)$ & 0.84 (0.59 to 1.54$)$ & 1.13 (0.81 to 1.58$)$ & 0.91 (0.55 to 1.48$)$ \\
\hline \multicolumn{6}{|l|}{$\mathrm{NO}_{2}$} \\
\hline Same-day & 29.0 & 0.99 (0.98 to 1.01$)$ & 0.99 (0.98 to 1.01$)$ & 1.07 (0.75 to 1.54$)$ & 1.00 (0.99 to 1.01$)$ \\
\hline 1-day lag & & $0.99(0.98$ to 1.00$)$ & 0.99 (0.98 to 1.01$)$ & 0.92 (0.70 to 1.20$)$ & 0.99 (0.98 to 1.01$)$ \\
\hline 3-day & & 0.99 (0.98 to 1.00$)$ & 0.99 (0.97 to 1.01$)$ & $1.16(0.78$ to 1.71$)$ & 0.92 (0.71 to 1.19$)$ \\
\hline \multicolumn{6}{|l|}{$\mathrm{O}_{3}$} \\
\hline Same-day & 99.5 & 0.80 (0.61 to 1.04$)$ & 0.94 (0.68 to 1.30$)$ & 1.12 (0.76 to 1.65$)$ & 0.94 (0.62 to 1.44$)$ \\
\hline 1-day lag & & 1.02 (0.77 to 1.36$)$ & 0.91 (0.67 to 1.24$)$ & $1.83(1.16 \text { to } 2.87)^{*}$ & 0.92 (0.59 to 1.42$)$ \\
\hline 3-day & & 0.99 (0.69 to 1.42$)$ & 0.94 (0.63 to 1.40$)$ & $1.90(1.06 \text { to } 3.42)^{*}$ & 0.91 (0.59 to 1.41$)$ \\
\hline
\end{tabular}

All ORs were adjusted for same-day, 1-day lag and 3-day temperature and relative humidity, respectively.

${ }^{*} \mathrm{P}<0.05$.

$\mathrm{CO}$, carbon monoxide; $\mathrm{NO}_{2}$, nitrogen dioxide; $\mathrm{O}_{3^{\prime}}$ ozone; $\mathrm{PM}$, particulate matter; $\mathrm{SO}_{2^{\prime}}$ sulfur dioxide.

and acute ischaemic stroke onset among patients $\geq 70$ years of age (data not shown). The test for heterogeneity of OR in agestratified analysis showed that the risk estimates were higher among patients aged 34-70 years old.

In the risk factor-stratified analysis, we observed a significant association between ischaemic stroke occurrence and PM10 levels (1-day lag: $\mathrm{OR}=1.51,95 \% \mathrm{CI} 1.10$ to 2.07 ; 3 -day mean: $\mathrm{OR}=1.57,95 \% \mathrm{CI} 1.08$ to 2.29 ) among patients with hyperlipidaemia from April to September. A significant association was also observed between ischaemic stroke onset and $\mathrm{O}_{3}$ levels (1-day lag: $\mathrm{OR}=1.83,95 \% \mathrm{CI} 1.16$ to 2.87 ; 3 -day mean: $\mathrm{OR}=1.90$, $95 \%$ CI 1.06 to 3.42 ) among those with hyperlipidaemia in the same period. In contrast, there were no significant associations between air pollutant exposures and ischaemic stroke occurrence among those without hyperlipidaemia (table 3), whereas the test for heterogeneity of these adjusted ORs among patients with and without hyperlipidaemia showed no difference. Other air pollutants (PM2.5, $\mathrm{SO}_{2}, \mathrm{CO}, \mathrm{NO}_{2}$ ) were not significantly associated with the occurrence of acute ischaemic stroke in subjects.

\section{DISCUSSION}

Our study summarised the associations between air pollutant exposures and acute ischaemic stroke onset in a stroke unit in Tianjin, China, between 1 April 2018 and 31 March 2019. The main findings were the significant association between PM10 exposure and ischaemic stroke occurrence among patients between 34 and 70 years old and the significant association between $\mathrm{PM} 10, \mathrm{O}_{3}$ exposure and ischaemic stroke occurrence among patients with hyperlipidaemia during the warm season (from April to September). The test for heterogeneity by age and hyperlipidaemia showed that risk estimates were higher among younger patients. In our study the risk estimates were based on the timing of symptom onset rather than on the date of hospital admission, which avoided some misclassification of time, ${ }^{18}$ and all risk estimates presented here were adjusted for meteorological variables (temperature and relative humidity). Besides, the case-crossover design was effective in controlling for many confounding factors and it was also a suitable method to control for season and day of the week. ${ }^{20}$

Many studies have reported the associations between air pollution and ischaemic stroke. ${ }^{101623}$ However, other authors did not find these relationships. ${ }^{24} 25$ Our main findings were consistent with several other studies that reported the association between PM10 and $\mathrm{O}_{3}$ exposure levels and ischaemic stroke occurrence. ${ }^{6812}$ We observed the association between acute ischaemic stroke onset and PM10 levels among patients between 34 and 70 years old from April to September. It is possible that air pollution exposure might vary by age and season. Older people usually spent more time indoors, whereas young-elderly residents spent more time outside during the warm season. ${ }^{26} 27$ Therefore the fixed-site monitoring data could better reflect exposures to outdoor air pollutants on warm days among the younger patients. In contrast, the risk estimates for the cold season may be underestimated. Weather factors could also modify the effects of air pollution. Some studies found that ischaemic stroke hospitalisations were associated with air pollutants 
only on warm days. ${ }^{1128}$ High temperatures were demonstrated to cause vascular endothelial dysfunction and increased platelet, cholesterol and haemoconcentration, thereby contributing to the occurrence of ischaemic stroke. ${ }^{29}$ During the study period, there were higher levels of $\mathrm{O}_{3}$ during the warm season in Tianjin, and further stratified analysis showed that both $\mathrm{O}_{3}$ and PM10 exposures were positively associated with ischaemic stroke onset among patients with hyperlipidaemia on warm days. The results suggested that people with hyperlipidaemia might be more susceptible to the harmful effects of $\mathrm{O}_{3}$ exposure than those with normal plasma lipid.

Several plausible biological pathways may be involved in the adverse health effects of air pollutants. Both gaseous air pollutants and particulate matter (PM) had adverse effects on health; however, many evidence showed that the most serious effects were related to PM, including PM10. ${ }^{30}$ These particles contain various toxic substances, and in metropolitan areas most PMs are anthropogenic, mainly originating from burning of fossil fuels. ${ }^{31}$ PM10 exposure could promote platelet activation, thereby contributing to thrombosis and coagulation. ${ }^{6}$ Findings in animal models also provided experimental evidence that PM10 exposure was related to inflammatory response by inducing the release of plasma proinflammatory cytokines, which may be associated with endothelial dysfunction and severity of brain ischaemia injury. ${ }^{32}$ However, more studies related to the effects of PM on humans and animals are needed to reveal the underlying mechanisms due to the complex composition of these particles. $\mathrm{O}_{3}$ is one of the most harmful gaseous air pollutants and is a powerful oxidising agent. $\mathrm{O}_{3}$ inhalation can promote increased oxidative stress and mitochondrial DNA damage, which could also lead to systemic inflammatory responses. ${ }^{33}$ The systemic inflammatory responses caused by PM10 and $\mathrm{O}_{3}$ exposure are also related to acceleration of atherosclerosis, playing a role in the development and progression of ischaemic stroke. ${ }^{34}$ People with hyperlipidaemia may have higher risk of atherosclerosis and may be more vulnerable to PM10 and $\mathrm{O}_{3}$ exposure.

The high pathogenic complexity of ischaemic stroke should be considered when interpreting our present results since it could lead to underestimation of the environmental effects. A Korean study suggested that short-term exposure to PM10 and $\mathrm{SO}_{2}$ was especially associated with cardioembolic stroke rather than large artery atherosclerosis and other non-cardioembolic strokes. ${ }^{36}$ However, other studies showed that PM10, PM2.5 and $\mathrm{O}_{3}$ exposure was associated with large artery atherosclerotic strokes, small vessel occlusions and lacunar strokes rather than cardioembolic strokes. ${ }^{12} 133738$ So air pollutants could variably affect different pathophysiological pathways, and the effect of air pollution on ischaemic stroke may differ among different ischaemic stroke subtypes, therefore leading to different outcomes. Moreover, geographical factors, air quantity monitoring stations, study design, adjusted confounding factors and some other factors varied in different works.

The strengths of this study included the validated stroke onset time, comprehensive medical data and the time-stratified crossover design. However, there were still some limitations. First, the study population was from a single institute only, which could limit the generalisability of the results. A larger multicentre study including more patients would better reflect the effects of air pollution on ischaemic stroke occurrence. Second, we did not analyse the effects of air pollution by ischaemic stroke subtype due to the small sample size. More efforts are needed since air pollutants may affect related pathophysiological pathways in various degrees. Third, average air pollution information was collected from fixed-site monitoring stations, and there would be exposure misclassification if air pollution at fixed sites is measured as individual exposure. So there may be some biases in our risk estimates, and the absence of associations with some pollutants in the study might have resulted from methodological disadvantages. Individual-level exposure measurements were considered to be superior when evaluating the health effects of outdoor air pollution. In the present study, most of the patients resided in urban Tianjin, and the average air pollution level in the urban area could reflect the average exposure level to some extent.

In conclusion, our study indicated that short-term outdoor air pollutant exposure was associated with ischaemic stroke occurrence in Tianjin. These associations were more evident during warm days. Associations between stroke occurrence and PM10 and $\mathrm{O}_{3}$ pollution exposure among subjects between 34 and 70 years old or subjects with hyperlipidaemia from April to September suggested that specific patient subgroups may be at increased risk of air pollution-related ischaemic stroke. Improving air quality may help prevent or reduce stroke occurrence, and some simple measures can be taken to reduce individual stroke risk, such as avoiding walking or exercising along traffic roads. Inflammatory responses may be involved in this process through plaque instability; however, the specific pathophysiological mechanism is still unclear. Further studies are needed to confirm our findings.

Contributors $X Q$ collected the data, performed the statistical analysis and drafted the manuscript. ZW, XG and XX collected the data and revised the manuscript. JX, GJ and YG collected the clinical data and revised the manuscript. SH, QY, ZC and XW collected the meteorological and air pollution data and revised the manuscript. LW revised the manuscript. SXL designed the study and revised the manuscript. $\mathrm{XL}$ designed the study, double-checked the statistical analysis and revised the manuscript.

Funding This work was supported by the Major Social Science Program of Tianjin Municipal Education Commission (grant number 2017JWZD36), Key Technology Research and Development Program of Science and Technology of Tianjin (grant number 18ZXDBSY00210), and Key Subject of Tianjin Health Committee (grant number 15KG136).

Competing interests None declared.

Patient consent for publication Not required.

Provenance and peer review Not commissioned; externally peer reviewed.

Data availability statement No data are available.

Open access This is an open access article distributed in accordance with the Creative Commons Attribution Non Commercial (CC BY-NC 4.0) license, which permits others to distribute, remix, adapt, build upon this work non-commercially, and license their derivative works on different terms, provided the original work is properly cited, appropriate credit is given, any changes made indicated, and the use is non-commercial. See: http://creativecommons.org/licenses/by-nc/4.0/.

\section{ORCID iDs}

Xuemei Qi http://orcid.org/0000-0002-3440-2273

Xin Li http://orcid.org/0000-0002-2977-5075

\section{REFERENCES}

$1 \mathrm{Kim}$ AS, Johnston SC. Global variation in the relative burden of stroke and ischemic heart disease. Circulation 2011;124:314-23.

2 Liu L, Wang D, Wong KSL, et al. Stroke and stroke care in China: huge burden, significant workload, and a national priority. Stroke 2011;42:3651-4.

3 Wang W, Jiang B, Sun H, et al. Prevalence, Incidence, and Mortality of Stroke in China: Results from a Nationwide Population-Based Survey of 480687 Adults. Circulation 2017;135:759-71.

4 Poorthuis MHF, Algra AM, Algra A, et al. Female- and male-specific risk factors for stroke: a systematic review and meta-analysis. JAMA Neurol 2017;74:75-81.

5 Olvera Alvarez HA, Kubzansky LD, Campen MJ, et al. Early life stress, air pollution, inflammation, and disease: an integrative review and immunologic model of social-environmental adversity and lifespan health. Neurosci Biobehav Rev 2018;92:226-42.

6 Franchini M, Mannucci PM. Thrombogenicity and cardiovascular effects of ambient air pollution. Blood 2011;118:2405-12. 
7 Chen G, Wang A, Li S, et al. Long-term exposure to air pollution and survival after ischemic stroke. Stroke 2019:50:563-70.

8 Liu H, Tian Y, Xu Y, et al. Association between ambient air pollution and hospitalization for ischemic and hemorrhagic stroke in China: a multicity case-crossover study. Environ Pollut 2017;230:234-41.

9 Shah ASV, Lee KK, McAllister DA, et al. Short term exposure to air pollution and stroke: systematic review and meta-analysis. BMJ 2015;350:h1295.

10 Tian Y, Liu H, Zhao Z, et al. Association between ambient air pollution and daily hospital admissions for ischemic stroke: a nationwide time-series analysis. PLoS Med 2018;15:e1002668.

11 Villeneuve PJ, Chen L, Stieb D, et al. Associations between outdoor air pollution and emergency department visits for stroke in Edmonton, Canada. Eur J Epidemiol 2006;21:689-700

12 Henrotin JB, Besancenot JP, Bejot Y, et al. Short-term effects of ozone air pollution on ischaemic stroke occurrence: a case-crossover analysis from a 10-year populationbased study in Dijon, France. Occup Environ Med 2007;64:439-45.

13 O'Donnell MJ, Fang J, Mittleman MA, et al. Fine particulate air pollution (PM2.5) and the risk of acute ischemic stroke. Epidemiology 2011;22:422-31.

14 Royé D, Zarrabeitia MT, Riancho J, et al. A time series analysis of the relationship between apparent temperature, air pollutants and ischemic stroke in Madrid, Spain Environ Res 2019;173:349-58.

15 Wang L, Guan Q, Wang F, et al. Association between heating seasons and criteria air pollutants in three provincial capitals in northern China: spatiotemporal variation and sources contribution. Build Environ 2018:132:233-44.

16 Ljungman PL, Mittleman MA. Ambient air pollution and stroke. Stroke 2014:45:3734-41.

17 Fang J, Yan W, Jiang G-X, et al. Time interval between stroke onset and hospital arrival in acute ischemic stroke patients in Shanghai, China. Clin Neurol Neurosurg 2011;113:85-8

18 Zeger SL, Thomas D, Dominici F, et al. Exposure measurement error in time-series studies of air pollution: concepts and consequences. Environ Health Perspect 2000:108:419-26.

19 Carracedo-Martínez E, Taracido M, Tobias A, et al. Case-crossover analysis of air pollution health effects: a systematic review of methodology and application. Environ Health Perspect 2010;118:1173-82.

20 Janes H, Sheppard L, Lumley T. Case-crossover analyses of air pollution exposure data: referent selection strategies and their implications for bias. Epidemiology 2005;16:717-26.

21 Altman DG, Bland JM. Interaction revisited: the difference between two estimates. BMJ 2003;326:219.

22 Guo Y-M, Wang J-J, Li G-X, et al. [Association between ambient temperature and hospital emergency room visits for cardiovascular diseases: a case-crossover study]. Zhonghua Liu Xing Bing Xue Za Zhi 2009;30:810-5.
23 Zhong $\mathrm{H}$, Shu Z, Zhou Y, et al. Seasonal effect on association between atmospheric pollutants and hospital emergency room visit for stroke. I Stroke Cerebrovasc Dis 2018;27:169-76.

24 Stockfelt L, Andersson EM, Molnár P, et al. Long-term effects of total and sourcespecific particulate air pollution on incident cardiovascular disease in Gothenburg, Sweden. Environ Res 2017;158:61-71.

25 Crichton S, Barratt B, Spiridou A, et al. Associations between exhaust and non-exhaust particulate matter and stroke incidence by stroke subtype in South London. Sci Total Environ 2016;568:278-84.

26 Cepeda M, Koolhaas CM, van Rooij FJA, et al. Seasonality of physical activity, sedentary behavior, and sleep in a middle-aged and elderly population: the Rotterdam study. Maturitas 2018;110:41-50.

27 You S, Tong YW, Neoh KG, et al. On the association between outdoor $\mathrm{PM}_{25}$ concentration and the seasonality of tuberculosis for Beijing and Hong Kong. Environ Pollut 2016;218:1170-9.

28 Tsai S-S, Goggins WB, Chiu H-F, et al. Evidence for an association between air pollution and daily stroke admissions in Kaohsiung, Taiwan. Stroke 2003;34:2612-6.

29 Lian H, Ruan Y, Liang R, et al. Short-Term effect of ambient temperature and the risk of stroke: a systematic review and meta-analysis. Int J Environ Res Public Health 2015;12:9068-88.

30 Schwarze $\mathrm{PE}$, Ovrevik J, Låg $\mathrm{M}$, et al. Particulate matter properties and health effects: consistency of epidemiological and toxicological studies. Hum Exp Toxicol 2006;25:559-79.

31 Brook RD. Cardiovascular effects of air pollution. Clin Sci 2008;115:175-87.

32 Guo L, Li B, Miao J-J, et al. Seasonal variation in air particulate matter (PM10) exposureinduced ischemia-like injuries in the rat brain. Chem Res Toxicol 2015;28:431-9.

33 Wang M, Sampson PD, Sheppard LE, et al. Long-term exposure to ambient ozone and progression of subclinical arterial disease: the multi-ethnic study of atherosclerosis and air pollution. Environ Health Perspect 2019;127:57001.

34 Aguilera I, Dratva J, Caviezel S, et al. Particulate matter and subclinical atherosclerosis: associations between different particle sizes and sources with carotid intima-media thickness in the SAPALDIA study. Environ Health Perspect 2016;124:1700-6.

35 Miyata R, Hiraiwa K, Cheng JC, et al. Statins attenuate the development of atherosclerosis and endothelial dysfunction induced by exposure to urban particulate matter (PM10). Toxicol Appl Pharmacol 2013;272:1-11.

36 Chung J-W, Bang OY, Ahn K, et al. Air pollution is associated with ischemic stroke via cardiogenic embolism. Stroke 2017;48:17-23.

37 Corea F, Silvestrelli G, Baccarelli A, et al. Airborne pollutants and lacunar stroke: a case cross-over analysis on stroke unit admissions. Neurol Int 2012;4:e11.

38 Wellenius GA, Burger MR, Coull BA, et al. Ambient air pollution and the risk of acute ischemic stroke. Arch Intern Med 2012;172:229-34. 